\title{
Physical and emotional impact of cadaver dissection on innovative medical education students: a survey in Ethiopia
}

\author{
Melese Shenkut Abebe \\ Department of Anatomy, School of Medicine, College of Medicine and Health Science, Wollo University, Dessie, Ethiopia
}

\begin{abstract}
Objectives: Although many studies have been conducted worldwide to investigate the positive and negative experiences of the cadaver room, there is no documented research in medical schools delivering the new innovative medical education (NIME) curriculum which involves teaching students who already receive a bachelor degree in any natural science including health sciences and having at least two years of work experience. Therefore, this study aimed to assess the effect of cadaver dissection both physically and emotionally on NIME students.

Methods: A survey was done on 82 first and second-year NIME students using standard structured questionnaire. The students were evaluated according to gender, religion and ethnicity.

Results: Students experienced multiple symptoms in the dissection room. The most prevalent physical symptoms were nausea (32\%), palpitation (20.7\%) and sweating (17.1\%). In addition to these, sadness (41.5\%), fear (34.1\%) and worry (29.3\%) were mostly reported emotional experiences. Females were more significantly nervous than males $(p=0.03)$. Students of Oromo ethnicity reported a significantly higher degree of fainting $(p=0.03)$, dizziness $(p=0.02)$, and palpitation $(p=0.02)$ than other ethnic students. Sweating and breathlessness were significantly decreased in year two compared to year one students $(p<0.05)$. The smell of the cadaver was the most stressing aspect of the cadaver room. Females had nightmares more significantly than males in the post-dissection period $(p=0.04)$.

Conclusion: Students experience a variety of physical and emotional symptoms during dissection. These can affect the performance of the students. this study provides data for these symptoms in NIME students, and their relation to gender, religion and ethnicity.
\end{abstract}

Keywords: cadaver dissection; emotional impact; medical students; physical impact

Anatomy 2018;12(3):145-151 (O2018 Turkish Society of Anatomy and Clinical Anatomy (TSACA)

\section{Introduction}

Anatomy, the study of the structures of the human body is one of the first, most basic and important subjects studied by medical students when they begin their medical education. ${ }^{[1]}$ Dissection of the dead human body has been central to medical education since Renaissance. ${ }^{[1,2]}$ Indeed, the Greek roots of the word anatomy indicate cutting apart; so, many anatomists are adamant that dissection is the best way to learn anatomy. ${ }^{[3,4]}$ Some scholars described dissection as the most universal and universally recognizable step in becoming a doctor. ${ }^{[2]}$ An old fashioned way of anatomy teaching in medical schools is based on the use of human cadaveric specimens, either taking the whole body specimens for complete dissection or as prosected specimens. ${ }^{[2]}$

In the 18th century, the study of gross anatomy was dependent on cadaveric dissection, because that was the only available method for three-dimensional studies of the gross anatomical structures. However, with the passage of time and, as a result of advances in science and technology, there have been revolutionary changes in teaching methodologies. ${ }^{[5]}$ In spite of that, cadaveric dissection cannot be dismissed as obsolete and is still of paramount importance in medical education. ${ }^{[4]}$ 
In addition, the use of the human body dissection for teaching medical students helps them to identify the real, natural and unbiased organs of the human being. It is also a means to learn anatomical variation before they are exposed to the real patient. This will let them prepare to face the challenges during their clinical practice. ${ }^{[6-8]}$

However, it is good to realize that cadaver dissection has multiple physical and psychological effects on students. These experiences especially worsen during the first period of dissecting the cadaver. ${ }^{[0]}$

In Ethiopia, there are two types of medical education curriculum; the conventional curriculum used to teach students directly coming from the high school, and the other called new innovative medical education (NIME) curriculum to teach students who already receive a bachelor degree in any natural science including health sciences and have at least two years of work experience.

Wollo University is one of the 13 institutions that launched the new NIME curriculum. In the NIME curriculum, the anatomy course is given as integrated with other basic science courses.

Therefore, dissection of the cadaver is done in the first two pre-clinical years of the NIME curriculum.

Multiple types of research have been conducted worldwide and indicated both positive and negative experiences of the cadaver room. ${ }^{[10-14]}$ However, there is no documented research conducted in medical schools delivering the NIME curriculum. This study aimed to assess the effect of cadaver dissection both physically and emotionally on NIME students.

\section{Materials and Methods}

This research was conducted on 85 first and second year NIME students of Wollo University in 2016. The students were informed about the objective of the study and the volunteer students were briefed on the questionnaire used as a data collection tool. A standardized questionnaire was used for data collection. The questionnaire includes sociodemographic characteristics and physical and emotional impacts of cadaver dissection on the students. The survey was done at one time after the first system dissection schedule for year one students, and after completion of all system dissection for the secondyear students. For the first-year students, those who didn't attend the first system dissection and repeaters were excluded from the study. In addition to this, for both year students, those who didn't avail at the time of data collection were also excluded. The ethical review committee of the School of Medicine, Wollo University approved this work earlier to data collection. The data were entered into Epi Info 7 (Centers for Disease
Control and Prevention, 2005) and analyzed using the Statistical Package for Social Sciences (SPSS for Windows, version 22.0, Armonk, NY, USA). $\mathrm{p}<0.05$ was considered as statistically significant.

\section{Results}

This study was conducted on 85 first and second-year new innovative medical students of Wollo University. From both years, 82 students filled the questionnaire. The average age range for most of the students $(70.7 \%)$ is $24-27$ years. $84.1 \%$ and $81.7 \%$ of the students were males and Ethiopian Orthodox Christian followers, respectively. The majority $(87.8 \%)$ of the students were from health science (paramedical science) educational background. In addition to this, $57.3 \%$ of the students were urban residents and $80.5 \%$ of them were Amhara in ethnicity as showed in Table $\mathbf{1}$.

In the present survey, most of the respondents 75 (91.5\%) agreed with the ethical acceptability of cadaver dissection for teaching medical students. All Muslim students agreed on the ethical acceptance of human body utilization for teaching purpose, while $89.6 \%$ of Christian students agreed. From a total of 82 students, $95.1 \%$ of them preferred cadaver dissections as the best method of learning anatomy and $75.65 \%$ of the students didn't think dissecting cadaver is replaced by other methods of teaching. Among the different teaching approaches on the cadaver, self or instructor assisted dissection was preferred by $92.7 \%$ of the students. Only $62.2 \%$ of the respondents were excited in the first visit of dissection room (Table 2).

Since most of the students $(87.7 \%)$ were from health science background $31.7 \%$ of them had previous exposure to the dead body. The previous exposure to dead body resulted in slight and high degree of trauma in $17.1 \%$ and $18.3 \%$ of the students, respectively.

The top three most stressing components of the dissection room were the smell of the cadaver $45.1 \%$, religious incompatibility $32.9 \%$, and touching a certain part of the cadaver $28 \%$ (Table 3). Females were more stressed by looking or touching certain parts of the cadaver and by the practical exam compared to males, while males were stressed by the smell, dissection workload, infectiousness of the cadaver and religious incompatibility. Looking at certain parts of the cadaver, smell of the cadaver, fear of infection and the practical exam were stressors for Christian students.

Nausea 32\%, palpitation $20.7 \%$ and sweating $17.1 \%$ were the most prevalent physical symptoms experienced in the dissection room. From the emotional symptoms reported by the students, sadness $41.5 \%$ was the first followed by fear (34.1\%) and worry (29.3\%) (Table 4). 
Table 1

Sociodemographic characteristics of the NIME students of Wollo University.

\begin{tabular}{|c|c|c|c|}
\hline Variables & & $\mathrm{n}$ & $\%$ \\
\hline \multirow[t]{4}{*}{ Age } & $24-27$ & 58 & 70.7 \\
\hline & $28-31$ & 22 & 26.8 \\
\hline & $32-35$ & 1 & 1.2 \\
\hline & $>35$ & 1 & 1.2 \\
\hline \multirow[t]{2}{*}{ Gender } & Male & 69 & 84.1 \\
\hline & Female & 13 & 15.9 \\
\hline \multirow[t]{2}{*}{ Religion } & Orthodox Christian & 67 & 81.7 \\
\hline & Muslim & 15 & 18.3 \\
\hline \multirow[t]{6}{*}{ Educational background } & Health sciences & 72 & 87.8 \\
\hline & Teaching & 1 & 1.2 \\
\hline & Applied sciences & 3 & 3.7 \\
\hline & Agriculture & 3 & 3.7 \\
\hline & Veterinary medicine & 1 & 1.2 \\
\hline & Other & 2 & 2.4 \\
\hline \multirow[t]{5}{*}{ Ethnicity } & Amhara & 66 & 80.5 \\
\hline & Oromo & 2 & 2.4 \\
\hline & Tigre & 8 & 9.8 \\
\hline & Gurage & 3 & 3.7 \\
\hline & Other & 3 & 3.7 \\
\hline \multirow[t]{2}{*}{ Residence } & Urban & 47 & 57.3 \\
\hline & Rural & 35 & 42.7 \\
\hline \multirow[t]{2}{*}{ Year of study } & Year one & 45 & 54.9 \\
\hline & Year two & 37 & 45.1 \\
\hline
\end{tabular}

Females were more nervous, depressed, sad and felt eye irritation than the males. On the other hand, males sweated, felt nausea, and fainted.

In religion comparison, Christian students commonly felt dry mouth, fear, depression, and satisfaction; in contrast, Muslim students showed nervousness, sadness, irritation of the eye and vomiting.

Oromo students significantly reported fainting, dizziness and palpitation as compared to the other three ethnic students $(\mathrm{p}<0.05)$. Although not statistically significant,

Table 2

Responses of the students on general information about cadaver dissection.

\begin{tabular}{|c|c|c|c|}
\hline Questions & Responses & n & $\%$ \\
\hline \multirow[t]{2}{*}{ Cadaver dissection is ethically acceptable } & No & 7 & 8.5 \\
\hline & Yes & 75 & 91.5 \\
\hline \multirow[t]{2}{*}{ Dissection is best method of learning Anatomy } & No & 4 & 4.9 \\
\hline & Yes & 78 & 95.1 \\
\hline \multirow[t]{2}{*}{ Cadaver dissection is replaced by other methods } & No & 62 & 75.6 \\
\hline & Yes & 20 & 24.4 \\
\hline \multirow[t]{3}{*}{ Preferred method of learning in the cadaver room } & Deal with prosected specimen & 5 & 6.1 \\
\hline & Self or instructor assisted dissection & 76 & 92.7 \\
\hline & Deal with dissected cadaver & 1 & 1.2 \\
\hline \multirow[t]{2}{*}{ First visit to the dissection room was exciting } & No & 31 & 37.8 \\
\hline & Yes & 51 & 62.2 \\
\hline \multirow[t]{2}{*}{ Have self-mental preparedness prior to the dissection room } & No & 10 & 12.2 \\
\hline & Yes & 72 & 87.8 \\
\hline
\end{tabular}


Table 3

Student's response of their most stressful component of the dissection room. For all comparisons $p>0.05$.

\begin{tabular}{|c|c|c|c|c|c|}
\hline \multirow[b]{2}{*}{ The most stressful component of the dissection room } & \multirow{2}{*}{$\begin{array}{c}\text { All \% } \\
(n=82)\end{array}$} & \multicolumn{2}{|c|}{ Gender (\%) } & \multicolumn{2}{|c|}{ Religion (\%) } \\
\hline & & Male & Female & Christian & Muslim \\
\hline Looking at certain part of the cadaver & 26.8 & 24.6 & 38.5 & 22.4 & 46.8 \\
\hline Touching certain part of the cadaver & 28.0 & 27.5 & 30.8 & 28.4 & 26.7 \\
\hline The smell of the body & 45.1 & 46.4 & 38.5 & 44.8 & 46.7 \\
\hline Dissection workload & 12.2 & 13 & 7.7 & 14.9 & 0 \\
\hline Religious incompatibility & 32.9 & 33.3 & 30.8 & 37.3 & 13.3 \\
\hline Fear of infection & 22.0 & 24.6 & 7.7 & 20.9 & 26.7 \\
\hline Thinking of practical exam & 17.1 & 15.9 & 23.1 & 14.9 & 26.7 \\
\hline
\end{tabular}

most of the physical and emotional symptoms were less likely to be seen in year one compared to second-year students. However, sweating and breathlessness were significantly less as $26.7 \%$ in year one compared to $5.4 \%$ in second-year, and $11.1 \%$ in year one compared to $0 \%$ in second-year students $(\mathrm{p}<0.05)$. Instead, nausea, palpitation, and dryness of the mouth were relatively higher for second-year students compared to the first year (Table 5).

The most common way of coping strategies used by the students in the cadaver room was focusing on task $46.3 \%(n=38)$ followed by seeking advice from instructor or lab assistant $43.9 \%(n=36)$ and thirdly stay within the group 25.6\% $(\mathrm{n}=21)$ as presented in Table 6. In addition to this, Christian students sought advice from lab assistant or their instructor, while Muslim students wanted to focus on their task as a coping mechanism in the dissection room. Females prayed and stayed in the group, and males sought an advice.

As shown in Table 7, most of the symptoms decreased gradually. However, loss of appetite and headache were still felt after leaving the dissection room. Both males and females, and Christian and Muslim students reported decrement symptoms after they left the cadaver room. However, female students reported insomnia which was statistically significant $(\mathrm{p}=0.04)$.

\section{Discussion}

Cadaver dissection has been used for a long time as a cornerstone of dealing anatomical science for medical education. Dissection of the human body helps students gets a

Table 4

Physical and emotional symptoms experienced by the students in the cadaver room.

\begin{tabular}{|c|c|c|c|c|c|c|c|c|c|}
\hline \multirow[b]{2}{*}{ Physical symptoms } & \multirow{2}{*}{$\begin{array}{l}\text { All }(\%) \\
(n=82)\end{array}$} & \multicolumn{2}{|c|}{ Gender (\%) } & \multicolumn{2}{|c|}{ Religion (\%) } & \multicolumn{4}{|c|}{ Ethnicity (\%) } \\
\hline & & Male & Female & Christian & Muslim & Amhara & Oromo & Tigre & Gurage \\
\hline Fainting & 4.9 & 5.8 & 0 & 4.5 & 6.7 & 3 & $50 *$ & 12.5 & 0 \\
\hline Dizziness & 12.2 & 11.6 & 15.4 & 11.9 & 13.3 & 9.1 & $100^{*}$ & 12.5 & 33.3 \\
\hline Nausea & 32.9 & 33.3 & 30.8 & 32.8 & 33.3 & 34.8 & 100 & 25 & 0 \\
\hline Vomiting & 3.7 & 4.3 & 0 & 3 & 6.7 & 1.5 & 50 & 12.5 & 0 \\
\hline Palpitation & 20.7 & 18.8 & 30.8 & 20.9 & 20 & 22.7 & $100 *$ & 0 & 0 \\
\hline Sweating & 17.1 & 18.8 & 7.7 & 16.4 & 20 & 18.2 & 50 & 12.5 & 0 \\
\hline Breathlessness & 6.1 & 5.8 & 7.7 & 6 & 6.7 & 6.1 & 50 & 0 & 0 \\
\hline Irritation of the eye & 9.8 & 7.2 & 23.1 & 6.7 & 10.4 & 7.6 & 100 & 33.3 & 33.3 \\
\hline Dryness of the mouth & 7.3 & 7.2 & 7.7 & 9 & 0 & 7.6 & 50 & 33.3 & 33.3 \\
\hline Worry & 29.3 & 30.4 & 23.1 & 32.8 & 13.3 & 31.8 & 0 & 38.5 & 0 \\
\hline Fear & 34.1 & 31.9 & 46.2 & 35.8 & 26.7 & 33 & 100 & 33 & 66.7 \\
\hline Satisfaction & 18.3 & 11.6 & 7.7 & 11.9 & 6.7 & 9.1 & 0 & 37.5 & 33.3 \\
\hline Sadness & 41.5 & 39.1 & 53.8 & 37.3 & 60 & 39.4 & 0 & 50 & 33.3 \\
\hline Depression & 14.6 & 11.6 & 30.8 & 14.9 & 13.3 & 15.2 & 50 & 12.5 & 33.3 \\
\hline Nervousness & 12.2 & 8.7 & $30.8^{*}$ & 10.4 & 20 & 10.6 & 50 & 33.3 & 33.3 \\
\hline
\end{tabular}

${ }^{*} p<0.05$. 
Table 5

Physical and emotional symptoms of the respondents by year.

\begin{tabular}{|c|c|c|c|}
\hline \multirow[b]{2}{*}{ Variables } & \multicolumn{2}{|c|}{$\begin{array}{c}\text { Year of study } \\
\text { n (\%) }\end{array}$} & \multirow[b]{2}{*}{$p$-value } \\
\hline & Year one & Year two & \\
\hline Fainting & $4(8.9)$ & 0 & * \\
\hline Dizziness & $6(13.3)$ & $4(10.8)$ & * \\
\hline Nausea & $12(26.7)$ & $15(40.5)$ & * \\
\hline Vomiting & $3(6.7)$ & 0 & * \\
\hline Palpitation & $9(20)$ & $8(21.6)$ & * \\
\hline Sweating & $12(26.7)$ & $2(5.4)$ & 0.011 \\
\hline Breathlessness & $5(11.1)$ & 0 & 0.036 \\
\hline Irritation of the eye & $5(11.1)$ & $3(8.1)$ & * \\
\hline Skin irritation & $2(4.4)$ & 0 & * \\
\hline Dryness of the mouth & $2(4.4)$ & $4(10.8)$ & * \\
\hline Worry & $13(28.9)$ & $11(29.7)$ & * \\
\hline Fear & $16(35.6)$ & $12(32.4)$ & * \\
\hline Satisfaction & $8(17.8)$ & $7(17.9)$ & * \\
\hline Sadness & $20(44.4)$ & $14(37.8)$ & * \\
\hline Depression & $9(20)$ & $3(8.1)$ & * \\
\hline Nervousness & $6(13.3)$ & $4(10.8)$ & * \\
\hline
\end{tabular}

${ }^{*} \mathrm{p}>0.05$.

meaningful and unbiased structure of human beings. In spite of this, students are experiencing a variety of physical and emotional symptoms at the time of dissection. These impacts can affect the performance of the students.

The ethical acceptability of cadaver dissection as agreed by most students irrespective of religion indicates that cadaver is a valuable gift to medical education. This is supported by the findings of Agnihotri and Sagoo ${ }^{[15]}$ and Rajeh et al. ${ }^{[16]}$

Our students agreed that cadaver dissection should not be replaced with plastic models or $3 \mathrm{D}$ images $(75.6 \%)$ and is the best method of learning anatomy (95.1\%). Self or instructor assisted dissection was preferred by $92.7 \%$ of our respondents to studying prosect- ed specimen or dissected cadaver. This is in close proximity with the findings of Agnihotri and Sagoo, ${ }^{[15]}$ Johnson, ${ }^{[17]}$ Shugaba et al., ${ }^{[18]}$ but different from the study of McLachlan et al. ${ }^{[2]}$ This difference may be due to the student's perception and level of understanding of new technology. Based on our findings, the idea of replacing the cadaver dissection technique with plastic models, computer-assisted training or other methods is challenged, as the utilization of human body dissection helps students to grasp the three-dimensional anatomy and concept of countless variations. ${ }^{[19]}$

This survey is intended to show the impacts of cadaver dissection immediately after the first-time dissection and after repeated dissections. Therefore, according to this investigation, nausea, palpitation and sweating were the

Table 6

Strategies used by students to help them cope with dissection. For all comparisons $p>0.05$.

\begin{tabular}{|c|c|c|c|c|c|}
\hline \multirow[b]{2}{*}{ Variables } & \multirow[b]{2}{*}{ All (\%) } & \multicolumn{2}{|c|}{ Gender (\%) } & \multicolumn{2}{|c|}{ Religion (\%) } \\
\hline & & Male & Female & Christian & Muslim \\
\hline Focusing on the task & 46.3 & 46.4 & 46.2 & 40.3 & 60.3 \\
\hline Self-prayer & 9.8 & 7.2 & 23.1 & 11.9 & 0 \\
\hline Stay within the group & 25.6 & 24.6 & 30.8 & 26.9 & 20 \\
\hline Temporary departure from the dissection room & 1.2 & 1.4 & 0 & 1.5 & 0 \\
\hline Seeking advice from lab assistance/instructors & 43.9 & 44.9 & 38.5 & 47.8 & 26.7 \\
\hline
\end{tabular}


Table 7

Responses on the symptoms that continue after leaving the dissecting room.

\begin{tabular}{|c|c|c|c|c|c|c|c|}
\hline \multirow[b]{2}{*}{ Symptoms } & \multirow[b]{2}{*}{ All (\%) } & \multicolumn{3}{|c|}{ Gender (\%) } & \multicolumn{3}{|c|}{ Religion (\%) } \\
\hline & & Male & Female & p-value & Christian & Muslim & p-value \\
\hline Loss of appetite & 40.2 & 40.6 & 38.5 & * & 41.8 & 33.3 & * \\
\hline Insomnia or nightmare & 13.4 & 10.1 & 30.8 & 0.04 & 14.9 & 6.7 & * \\
\hline Dizziness & 11.0 & 10.1 & 15.4 & * & 10.4 & 13.3 & * \\
\hline Headache & 22.0 & 18.8 & 38.5 & * & 20.9 & 26.7 & * \\
\hline Loss of concentration on study & 13.4 & 11.6 & 23.1 & * & 14.9 & 6.7 & * \\
\hline Symptoms decrease gradually & 90.2 & 91.3 & 84.6 & * & 88.1 & 100 & * \\
\hline
\end{tabular}

${ }^{\star} p>0.05$

most prevalent physical symptoms experience in the dissection room. This finding is almost consistent with a research conducted in Tanzania at Muhimbili University which showed disgust, fear, nausea, loss of appetite and sweating as the commonest symptom. ${ }^{[1]]}$ Another research done in India by Vinay et al. ${ }^{[20]}$ indicated the commonest symptoms as eye irritation $(63.33 \%)$, headache $(10 \%)$, decrease in appetite (12\%), nausea (3.3\%) and sweating (35.33\%).

The research conducted in Foundation University Medical College, Rawalpindi, Pakistan pointed out eye soreness and fatigue (39.9\%) and throat irritation (41.6\%) as the most common physical symptom. This finding was different from ours, possibly due to different laboratory setup, age and educational background of our students as our study subjects had a minimum of bachelor degree. ${ }^{[21]}$

The most prevalent emotional symptoms depicted in this research were sadness, fear and worry. This finding is also similar to the above researchers.

In the comparison done between males and females, females were more nervous than males. This variable showed a significant difference $(\mathrm{p}=0.03)$. This may indicate a gender difference in behavioral response to cadaver dissection. ${ }^{[2]}$ Students with Oromo ethnicity reported a significantly higher degree of fainting $(\mathrm{p}=0.03)$, dizziness $(\mathrm{p}=0.02)$, and palpitation $(\mathrm{p}=0.02)$ than other ethnic students. No significant differences were found for the other symptoms.

As presented in Table 6, this study also compared the decrement of the symptoms between the two batch students. The prevalence for most of the symptoms decreased for the second-year students. This is because of repeated exposure to the dissection. This finding was also reported in other studies. ${ }^{[2,23,24]}$

According to a research conducted in Hawasa University and the University of Gondar, Ethiopia, most stressing component of the dissection room was the smell of the dissection room. This is also the same in this study as stated by $45.1 \%$ of the respondents, and also in line with the study of Bataineh et al. ${ }^{[25]}$ This is because of the established use of formalin as a preservative of cadavers in our country, Ethiopia. ${ }^{[24,26]}$ There were some ups and downs in the frequency of responses between males and females, and Christians and Muslims; however, none of these were statistically significant.

In this study, $90.2 \%$ of the symptoms decreased gradually. However, loss of appetite, headache, and nightmares were still felt after leaving the dissection room. Post-dissection continuity of the above two symptoms may be due to long time (minimum of 3 hours) exposure at one dissection schedule. This may lead to an excessive intake of irritant chemical (mainly formalin) that may bring loss of appetite and headache. Females had nightmares more than males in the post-dissection period $(p=0.04)$. Nevertheless, no significant difference was observed in Christian and Muslim respondents. Karau et al. ${ }^{[27]}$ presented similar findings.

The commonest way of coping strategy used by the students was focusing on task followed by seeking advice from instructor or lab assistant and thirdly stay within the group. Comparison of gender and race presented in Table 7 did not show a significant difference between males and females and Christians and Muslims. Most students in Oman $(65 \%)$ and Jordan (89.8\%) used rationalization to cope with fear and disturbance associated with cadaver dissection. ${ }^{[28]}$ Other coping mechanisms listed in this research are utilized in different degrees by the above students. The age and work experience of our subjects may be the factors that bring a difference in prioritizing coping mechanisms.

This study has some limitations having incorporated only two batches of medical students, of a number of 85 . On the other hand, the concentration of embalming fluid on air in the dissection room could not be measured due to our laboratory facilities. 


\section{Conclusion}

Even though dissection of the human body is the best methods of learning anatomy, multiple physical and emotional symptoms are experienced by the students. Commonly students felt nausea, palpitation, sweating sadness, fear, and worry in our cadaver room. Even some of the symptoms are worsen for female. These findings are also reported by different investigators. Therefore, all medical schools of Ethiopia should conduct nation-wide research to assess commonest symptoms, their causes and the maximum level of embalming solution in the cadaver room.

\section{Acknowledgments}

The deepest gratitude is extended to the students who voluntarily participated to fill in the questionnaire.

\section{References}

1. Parker LM. What's wrong with the dead body? Use of the human cadaver in medical education. Med J Aust 2002;176:74-6.

2. McLachlan JC, Bligh J, Bradley P, Searle J. Teaching anatomy without cadavers. Med Educ 2004;38:418-24.

3. O'Carroll RE, Whiten S, Jakson D, Sinclair DW. Assessing the emotional impact of cadaver dissection on medical students. Med Educ 2002;36:550-4.

4. Snelling J, Sahai A, Ellis H. Attitudes of medical and dental students to dissection. Clin Anat 2003; 16:165-72.

5. Hancock D, Williams M, Taylor A, Dawson B. Impact of cadaver dissection on medical students. New Zealand Journal of Psychology 2004;33:20-3.

6. Cahill KC, Ettarh R. Attitudes to anatomy dissection in an Irish medical school. Clin Anat 2009; 22:386-91.

7. Older J. Anatomy: a must for teaching the next generation. Surgeon 2004; 2:79-90.

8. Rajkumari A, Singh Y. Body donation and its relevance in anatomy learning - a review. J Anat Soc India 2007; 56:44-7.

9. Nnodim J. Preclinical student reactions to dissection, death, and dying. Clin Anat 1996;9:175-82.

10. Dempster M, Black A, McCorry N, Wilson D. Appraisal and consequences of cadaver dissection. Med Educ Online 2006; 11:4592.

11. Russa A, Mligiliche L. Inspiring Tanzanian medical students into the profession: appraisal of cadaveric dissection stress and coping strategies. Ital J Anat Embryol 2014; 119:268-76.
12. Tschernig T, Schlaud M, Pabst R. Emotional reactions of medical students to dissecting human bodies: a conceptual approach and its evaluation. Anat Rec 2000;261:11-3.

13. Vijayabhaskar P, Shankar PR, Dubey AK. Emotional impact of cadaver dissection: a survey in a medical college in western Nepal. Kathmandu Univ Med J (KUMJ) 2005;3:143-8.

14. Williams AD, Greenwald EE, Soricelli RL, DePace DM. Medical students' reactions to anatomic dissection and the phenomenon of cadaver naming. Anat Sci Educ 2014;7:169-80.

15. Agnihotri G, Sagoo MG. Reactions of first year Indian medical students to the dissection hall experience. National Journal of Integrated Research in Medicine 2010;1:4-9.

16. Rajeh NA, Badroun LE, Alqarni AK, Alzhrani BA, Alallah BS, Almghrabi SA, Almalki LA. Cadaver dissection: a positive experience among Saudi female medical students. Journal of Taibah University Medical Sciences 2017; 12:268-72.

17. Johnson JH. Importance of dissection in learning anatomy: personal versus peer teaching. Clin Anat 2002; 15:38-44.

18. Shugaba AI, Usman YM, Shimwen FJ, Uzokwe CB, Shinku F, Rabiu AM, Hassan ZI. Attitude of Jos University medical students to their initial encounter with cadavers in the dissecting room. Journal of Experimental and Clinical Anatomy 2015;14:101-4.

19. Winkelmann A. Anatomical dissection as a teaching method in medical school: a review of the evidence. Med Educ 2007; 41:15-22.

20. Vinay KV, Martin LA, Vishal K, Pradeep K. Attitude of first year Indian medical students towards cadaver dissection. International Journal of Anatomy and Research 2015;3:1255-58.

21. Khan H, Mirza T. Physical and psychological effects of cadaveric dissection on undergraduate medical students. J Pak Med Assoc 2013; 63:831-4.

22. Izunya A, Oaikhena G, Nwaopara A. Attitudes to cadaver dissection in a Nigerian medical school. Asian Journal of Medical Sciences 2010;2:89-94.

23. Lee Y, Lee Y, Kwon S, Park S. Reactions of first-year medical students to cadaver dissection and their perception on learning methods in anatomy. Korean J Med Educ 2011;23:275-83.

24. Getacew D. Reaction of medical students to experiences in dissection room. Ethiop J Health Sci 2014;20:337-42.

25. Bataineh ZM, Hijazi TA, Hijleh MF. Attitudes and reactions of Jordanian medical students to the dissecting room. Surg Radiol Anat 2006;28:416-21.

26. Mulu A, Tigabu D. Medical atudents' attitudinal changes towards cadaver dissection. Ethiop J Health Sci 2012;22:51-8.

27. Karau PB, Wamachi A, Ndede K, Mwamisi J, Ongeti K. Physical and emotional impact of dissection: findings from a pioneer medical class in a Kenyan Medical School. Anatomy Journal of Africa 2016;5:746-59.

28. Abu-hijleh MF, Hamdi NA, Moqattash ST, Harris PF, Heseltine GF. Attitudes and reactions of Arab medical students to the dissecting room. Clin Anat 1997;10:272-8.

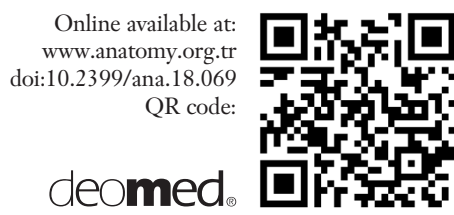

Correspondence to: Melese Shenkut Abebe, MSc Department of Anatomy, School of Medicine, College of Medicine and Health Science, Wollo University, Dessie, Ethiopia

Phone: +251912368 855

e-mail: melese19@yahoo.com

Conflict of interest statement: No conflicts declared.

This is an open access article distributed under the terms of the Creative Commons Attribution-NonCommercial-NoDerivs 3.0 Unported (CC BY-NCND3.0) Licence (http://creativecommons.org/licenses/by-nc-nd/3.0/) which permits unrestricted noncommercial use, distribution, and reproduction in any medium, provided the original work is properly cited. Please cite this article as: Abebe MS. Physical and emotional impact of cadaver dissection on innovative medical education students: a survey in Ethiopia. Anatomy 2018;12(3):145-151. 